\title{
Quality Management of Transport Services: Concept, System Approach, Models of Implementation
}

\author{
Oksana Kryvoruchko $^{1 *}$, Vladimir Shynkarenko ${ }^{1}$, Nadezhda Popova ${ }^{2}$ \\ ${ }^{1}$ Kharkiv National Automobile and Highway University \\ ${ }^{2}$ Kharkiv Institute of Trade and Economics of Kyiv National University of Trade and Economics \\ *Corresponding author_E-mail: oksana_kryvoruchko@i.ua
}

\begin{abstract}
The article proposes a conceptual approach to transport services quality management. It is based on the principles of logistical management, management of relationships with consumers, harmonization of the enterprise management system based on the quality and the use of principles of a synergetic systemic approach. The synergetic systemic approach presupposes the formation of a self-organizing quality management system for transport services (cybernetic adaptive, in which the accumulation of experience, the memorization and structuring of information is expressed in a change in the structure of the system and the level of its organization). The scientific novelty of the proposed approach to transport services quality management consists in the integration of the principles of the TQM concept and logistics, the application of a variable approach to selecting technologies for improving the processes of transport and logistics services; comparison of consumer assessment of motor transport services with an evaluation of the quality of processes of its formation. The proposed methodological approach to evaluation takes into account the influence of integrated processes on the final result formation, as well as the effectiveness of each process execution. The implementation of this approach will provide a reasonable choice of methods for providing and improving the quality of transport services, the effectiveness of creating/improving the management system.
\end{abstract}

Keywords: Logistical management; quality management; quality of transport services; quality management system; transport services.

\section{Introduction}

In modern conditions, the quality problem occupies a central place in the activity of any enterprise. The creation of conditions for further development of the transport complex, its integration into the European and world transport systems predetermine the priority of this problem for road transport enterprises. There is a positive trend towards the development of the logistics services market; the increase in the volume of cargo transportation (in 2017, the increase in the turnover of goods accounted for almost $10 \%$ compared to the previous year, while the entire volume of freight turnover falls on the road transport). The development of a trucking enterprise focused on servicing a large number of consumers; increasing their level of exactingness should be very dynamic; the volume and quality of transport services provided should meet the expectations and requirements of consumers. An effective solution to the problem of quality assurance is possible provided that the modern concepts, approaches to management are used. At the same time, the approaches used to manage the quality of transport services are associated with the following shortcomings: the relationship with consumers of services is not taken into account (there are no mechanisms for involving them in the production preparation process, the deployment of quality requirements for transport services, etc.); it is not supposed to regulate the quality of transport products during the development and implementation of the technological process, in particular there is no systematic development of preventive actions (such as algorithms, the scope of such impacts is not justified, etc.); the processes and procedures for quality management are not sufficiently developed; the principles of logistics management are not fully used.

This calls for conducting scientific research towards the development of modern concepts, approaches to quality management of transport services.

\section{Literature Review}

The development of theoretical fundamentals of transport services quality management is associated with a certain concept, i.e. a combination of the most significant theoretical views on the understanding and definition of its essence, content, principles, as well as conditions of incubation and implementation.

Currently, the following basic concepts of quality management are actively applied [1-2]: 1) Total Quality Management - TQM; 2) lean production (identification and elimination of processes that do not bring an added value); 3) Kanab (ensuring timely delivery of products to the customer); 4) Kaizen (continuous improvement of the internal organization processes with minimal expenditure of resources and involvement of employees in the process of implementing improvements); 5) Six Sigma (minimizing the number of inconsistencies per one million opportunities) [3].

The concept of TQM has become most widespread. Its key idea is that the company should not only work on the quality of the goods produced, but also on the quality of organizing all business processes within an enterprise. This is achieved by the following: strict conformity of products (services) to the requirements and expectations of the end user; clear planning of work; preparation of quality documentation; availability of external and internal quality resources. 
Based on these concepts, taking into account the specific features of production and the realization of specific types of products, theoretical views and methodological approaches to quality management are formed, as well as new concepts (i. e., the marketing concept [4], the approach to the quality of service from an economic point of view [5], implemented through the strategies of ensuring the cost-effective quality: a dual culture strategy (a full set of high-quality services at a low price due to the ambitions of management and the contextual ambivalence), process management, high specialization, that is a single type of services for a highly-oriented segment of customers). Much attention is paid to the study of psychosocial factors affecting the behavior of passengers in the public transport [6, 7]; approaches to the organization of a single stream space (logistics), rapid response to a failure at any point of the process, and interference with the process [8].

Analysis of conditions for implementing these concepts with regard to the management of the quality of transport services makes it possible to conclude that their specifics require specification of individual approaches and implementation methods, using the principle of a system-forming role of logistics management, the development and creation of harmonized systems for management of a motor transport enterprise on the basis of quality, etc.

\section{Results and Findings}

This paper proposes the concept of transport services quality management (Fig. 1), which reflects a holistic view of the system of basic ideas for achieving and ensuring the required level of transport services.

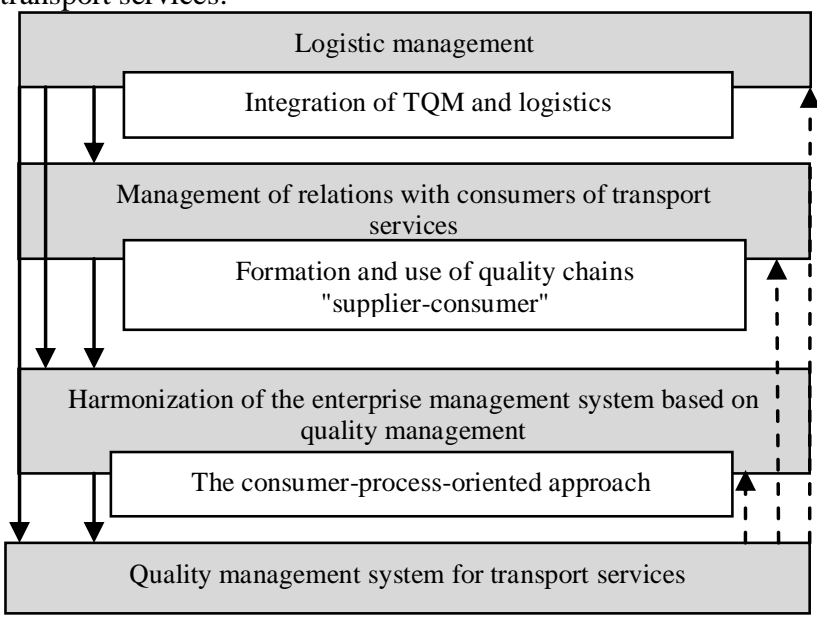

Fig.1: The concept of transport services quality management.

At the heart of the concept of transport services quality management, it is expedient to envisage the formation and implementation of logistics management [9]. In general, the logistic management is: firstly, the process of administering the logistics system, i.e. the performance of basic management functions (with the use of information and computer technologies) to achieve the goals of the logistics system; secondly, it includes management of changes in the organization, management of personnel; thirdly, its strategic aspect is connected with the activity on setting goals, global and common tasks for the logistic system of an enterprise and maintaining the company's mutual relations with the external environment, which provides an opportunity to achieve the goals that correspond to its internal capacity and to flexibly respond to external factors.

Logistic management and quality management are a common process of organization of production at an enterprise, aimed at increasing the efficiency of using the available material, financial, information and human resources. At the same time, the quality determines which product or service needs to be produced, taking into account the requirements of consumers and norms, and logistics determines how to achieve the required level of production, the level of organization of processes and the level of costs.

Logistic quality management provides, on the one hand, the application of principles and methods of logistics for quality management, and on the other hand, the formation of a logistics system of the relevant organization with adequate management effects on the quality as an entity of management. At the same time, the use of logistic management is carried out not only from the positions of technical and operational indicators of transport, financial indicators, but also from the position of personnel, i.e. through motivation, and monitoring.

Consequently, logistic management in the management of the quality of transport services is aimed at integrating the basic principles of TQM and logistics (customer focus, the defining role of management in enterprise reform activities based on the principles of TQM, strategic planning, involving all employees, staff training, using motivation methods, process management, quality of suppliers, an information system, application of benchmarking, constant evaluation of the efficiency of the quality of management system functioning, a process approach to the logistics flow and the flow of quality formation, an integration of the functions of forming economic ties with the functions of planning, organizing and managing stream processes, coordinating the strategy and tactics of management in all links of the logistics chain and the processes of quality formation).

Integration of both TQM and logistics will provide a common emphasis in the organization of material flows and the quality as a flow; to create and maintain partnerships between interacting transport companies, as well as their customers (cargo owners) on the basis of mutual interests and trade-offs, and to ensure the dynamics of their convergence.

The next direction of the concept of quality management of transport services is the management of relationships with consumers, which is a permanent, purposeful process used for the formation and development of relations with consumers of transport services based on the desire to achieve mutually beneficial solutions. The use of the provisions of relationship management is conditioned by the targeted orientation of this process to meet the requirements of consumers to the quality of services rendered, to increase their satisfaction and, on this basis, to form long-term relationships.

While working with consumers, various kinds of information systems are used, among them the frontline information system (FIS); Customer Relationship Management (CRM); and the Sales Expert system as an example of a CRM application.

In order to create (maintain) long-term and mutually beneficial relations between the consumer and the enterprise, which enable the enterprise to provide such transport services, the quality of which would satisfy the consumers, it is necessary to develop a special system, the elements of which will be presented by a transport enterprise (subject of management) and consumers (object of management). In this case, the object of management (the consumer) is proposed to be endowed with the attributes of a self-organizing system, and the interaction between the subject and the object should be envisaged as participatory.

A self-organizing system is a cybernetic adaptive system in which the accumulation of experience, the memorization and structuring of information is expressed as a change in the structure of the system and the level of its organization. In this case, the selforganizing system can be self-adjusting, self-developing and selflearning. Self-adjustment of the system involves the accumulation of experience (information storage), which is expressed in the change of certain parameters essential for the purpose of the system. So, the consumer can change the preferences concerning separate characteristics of services, their volumes, and the ways they are rendered.

Self-development of the system is conditioned by the development of the goal of its development, the criteria for achieving them, parameter and structure variation, etc.; self-learning, that is the ability to independently seek quality criteria for its functioning, based on accumulated experience. 
Unlike traditional management (the manager makes decisions while the subordinate carries out decisions), the participatory management assumes joint participation of the head and the subordinate (subject and object) in the managerial process. At the same time, the participatory management can be implemented in the following areas: firstly, the involvement of the consumer in setting goals with regard to the services provided as well as their quality, and the relationships. Secondly, the consumers are given the right to supervise the quality of transport services provided. Thirdly, the participatory management presupposes a broad participation of consumers in rationalization activities, in making proposals to improve certain elements of the service process and in general, the provision of services, and participation in solving problems. It should be noted that the presented directions should be used in a certain combination, as they are closely related and complementary.

Implementation of management of mutual relations with consumers of transport services will make it possible to provide effective formation and the use of quality chains «supplierconsumer».

In the concept of TQM, the emphasis on the consumer does not mean the satisfaction of only external but also internal consumers. Participants of the product life cycle form a continuous and interconnected chain, which is sometimes called a quality chain. At the same time, any employee of the organization, acting on the final product, can operate as an internal consumer, regardless of direct participation in its creation. The employee, as an internal consumer, receives material (raw materials, products, information, etc.) from the supplier (suppliers), that is the external (supplier organization) or another employee who acts as an «internal supplier», processes it (occur certain transformations ) and transfers it to another person for further production, acting as an "internal supplier". In this case, the quality is divided into external and internal one. In order to satisfy the external consumers (provide external quality), it is necessary to satisfy the internal consumers (receive internal quality).

Harmonization of the enterprise management system based on the quality management means its penetration into other subsystems, inclusion into their formation and functioning as a necessary subsystem. Harmonization processes do not only provide the unification of various management subsystems in a common system, but also the effective interaction of these subsystems.

Harmonization of the enterprise management system is achieved as a result of the coordinated interaction of its constituent elements, which provides it with new properties that have integrative properties, ensuring the most effective achievement of the objectives pursued by an enterprise.

The system of general management of an enterprise is aimed at the adoption of strategic, general and long-term solutions (establishment of regulatory requirements and management policies, innovation policies, planning, organization of work, motivation, coordination, inspection, and responsibility definition). It should be noted that the overall objectives of an enterprise cannot be achieved without ensuring the necessary level of quality. For example, in practical terms, a long-term goal is formulated as "to become a leader in product output" and is decomposed into such sub-goals: to support the ability to produce products that maximally meet the requirements of consumers; maintain a high level of trust on the part of consumers and other stakeholders, etc. The same goals are formulated by the quality management system.

Functional subsystems are aimed at managing various functions of an enterprise: production, material and technical supply, finance, personnel, marketing, etc. At the same time, the quality management system is aimed at achieving the required level of quality of the relevant processes and their results. When managing the production it includes the quality of products or services produced; at management of material and technical supply it implies the quality of input resources (materials, engineering, etc.); at management of the finance it presupposes the quality of financial processes implementation at an enterprise, etc.
The target subsystems are associated with the implementation of specific objectives encountered by an enterprise within a certain period of time: i. e., managing the enterprise competitiveness, the product competitiveness, the productivity, and the labor potential, etc. The quality management system ensures the quality of setting goals, the quality of implementing the required set of work.

The providing subsystems (equipping with technical means, information, legal, material provision, etc.) are aimed at establishing the level of quality and organizational conditions for providing the "input" of the system with everything necessary for its normal functioning.

The quality management system acts as the coordinator of functioning of all subsystems. Its main objectives for coordination are the selection of an appropriate method, appropriate in relation to the achievement of specific tasks facing a specific control subsystem. Depending on the priority of these tasks, the capabilities of the enterprise, the competence of the personnel and other factors, different methods of coordination should be chosen:

- coordination through «interaction forecasting» - the quality management system is a link for the functioning of other subsystems (in choosing optimal management decisions, the necessary parameters of quality serve as the criterion);

- coordination through "evaluation of interactions" - the quality management system specifies the range of signal changes for other control subsystems - the quality parameters are the limiting conditions in the development and implementation of relevant administrative impacts;

- "decoupling of interactions" - the managing subsystems act autonomously, independently choosing the connecting signals (in case of the need to maintain the quality level of various processes, work, products at a certain level).

The practical result of harmonization of the enterprise management system is the application of the consumer-process approach to management, as well as the formed quality management system for transport services.

The consumer-process approach to transport services quality management provides for (Fig. 2):

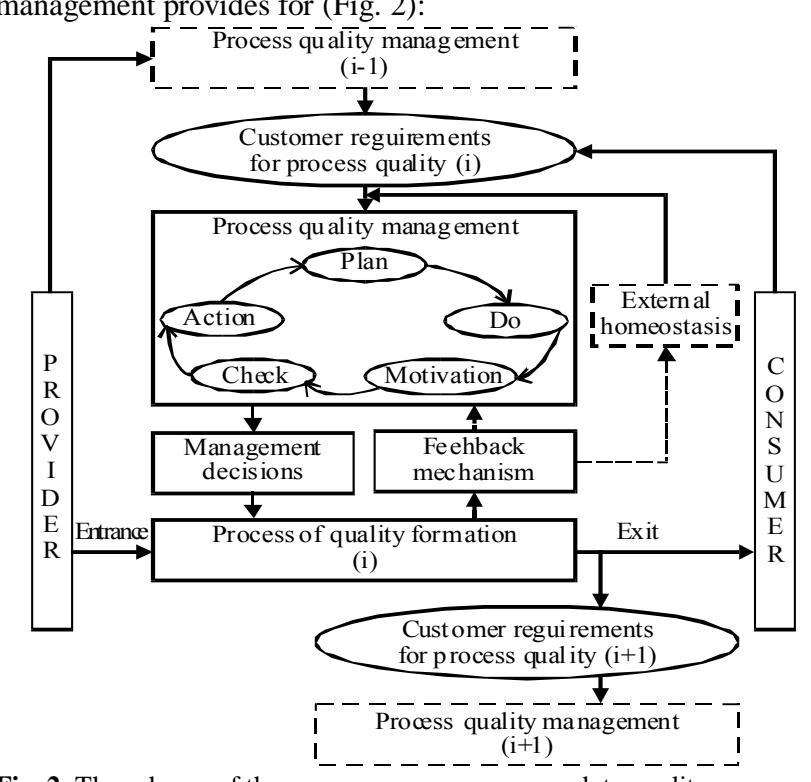

Fig. 2: The scheme of the consumer-process approach to quality management.

1) representation in the form of process models of a managed object (quality formation processes) and a managing entity (quality management processes). The process quality management is organized on the basis of the Plan-Do-Check-Action cycle with the inclusion of the additional Motivation function. This is necessary to ensure the leading role of the personnel in achieving the required level of quality;

2) the organization of management for certain interrelated cycles corresponding to the possible categories of consumers of an enterprise; 
3) ensuring the management of the requirements of consumers and the objectives of the relevant processes of quality formation;

4) a more branched and improved feedback mechanism, which makes it possible to manage the quality indicators of the relevant processes, the requirements of consumers, the objectives, and their implementation;

5) the use of mechanisms of external and internal homeostasis (self-regulation, ensuring a stable state of equilibrium of the open system in its interaction with the environment). With the help of external homeostasis, the integrity of management systems is ensured in interactions with the external environment (the process objectives are determined on the basis of specific conditions); the internal homeostasis provides an independent response of the processes of quality formation to impacts that disrupt their normal functioning.

The application of the consumer-process approach will allow an enterprise to avoid internal contradictions, taking spontaneous or narrow-minded decisions in the field of quality.

The quality management system for transport services is developed on the basis of a synergetic system approach, in which systems are considered to be complex, open, nonlinear with the characteristics of instability, nonequilibrium, bifurcation, selforganization, dissipation, etc. The proposed structure of objects in the management of the quality of transport services is built on the basis of integrated processes of its formation and the definition of inputs and outputs as the results of their implementation. Regardless of the process location in the overall structure, one of the outputs is the quality of various types of resources: information, tools and objects of labor. The determining input to the consumer process is the information about the possible ways to satisfy the existing needs, etc. The output is the requirements to the quality of services, which in turn are fed to the input to the customer service processes, determining their component operations, speed, and resources, etc. The output of these processes is the functional and instrumental quality, which is directly the quality of the auto-transport service and the requirements to the quality of production training. All types of processes, their "inputs" and "outputs" included into the system of objects in the management of quality at an ATE are implemented similarly.

The structure of subjects of transport services quality management includes the implementation of management functions during the expanded (Fig. 3) and elementary cycles.

The application of the CPI block is due, firstly, to a constant change in the market requirements, individual consumers, therefore, the need to introduce changes into the service process, conditions, motivation, etc. Secondly, it is due to the opportunity to ensure a more complete implementation of the TQM principle, which means continuous improvement. The operation of the $C P I$ block involves the development and implementation of a program directed to continuously improve the quality of the services provided, as well as the overall efficiency of the customer service process. Measures to improve the quality of service processes are developed based on: any changes in the market needs that require the introduction of changes into the types of services provided; any deviations from the established quality parameters of the service rendered as well as the customer service process due to inefficiency or inadequacy of control techniques; reserves of cost reduction while maintaining and improving the quality of the services rendered.

The elementary cycle is also implemented by functions that are combined into blocks $D, R, I$. In block $\mathrm{D}$, operative quality planning is performed, i.e. making certain changes in the structure of the customer service process, the methods of service, etc.

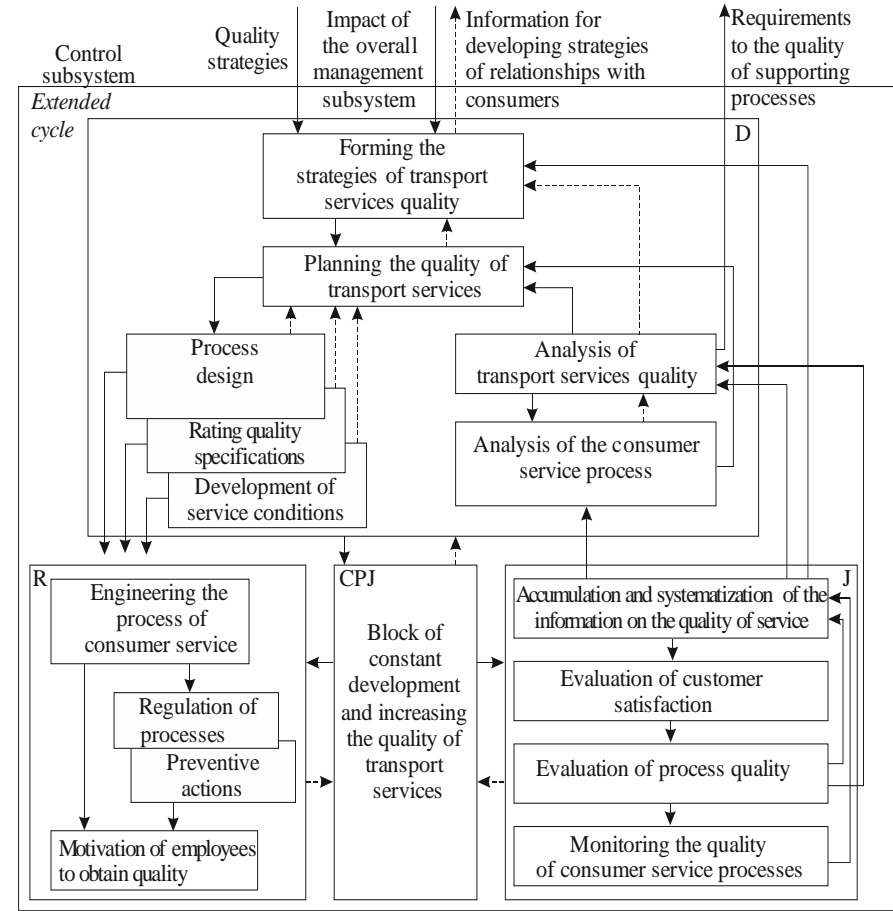

Fig. 3: The scheme of quality management system for transport services (extended cycle).

Block $R$ is aimed at developing specific tasks by the executor of the given process and, if necessary, performing corrective actions to carry out the process. The information-control block $I$ registers the data on the quality of the customer service processes performed, identifies and defines various types of inconsistencies, as well as makes it possible to analyze the occurrence of identified non-conformities. At the same time, it is intended to focus attention on individual operations of the customer service process to influence the process in question with the help of corrective feedback based on the results of measurements.

To implement the work of the proposed system of transport services quality management, a special algorithm has been developed (Fig. 4).

Based on the requirements of consumers to the quality of transport services, the potential opportunity for their satisfiability (availability of the necessary rolling stock, material and labour resources, the possibility of organizing optimal routes, logistics and other factors) is determined.

Further, it is necessary to introduce changes into the process of providing transport services. If such a need is established, then conversion technologies for improving the process are selected, otherwise procedural technologies. Transformational technologies («from the process to the structure») are focused on creating additional value for internal and external customers; research of processes from the standpoint of a set of operations that create the value for the consumer; application of internal marketing. The implementation of such technologies involves direct and reverse process reengineering.

The procedural technology of improvement («from structure to process») is based on the creation of a system for recording the quality of the operations and processes that are being performed, makes it possible to record the positive dynamics for certain indicators. This approach is focused on improving the fragmentary processes within the framework of functional and specialized management structures, their unification and ISO standardization. The main methods of implementing the procedural technology for improving processes are the "Kaizen" and "6 sigma" methods. After introducing appropriate changes into the process of providing transport services and practical implementation of a new model, the quality assessment is carried out. The evaluation of external (consumer) and internal quality is proposed.

The assessment of the quality of transport services from the standpoint of the consumer (external quality) is based on a 
comparison of a set of requirements that the customer places on the service process, which is in practice expected and perceived by the consumer of quality level [10]. The importance of meeting the relevant requirements and the degree of their manifestation is established by interviewing consumers before providing the service.

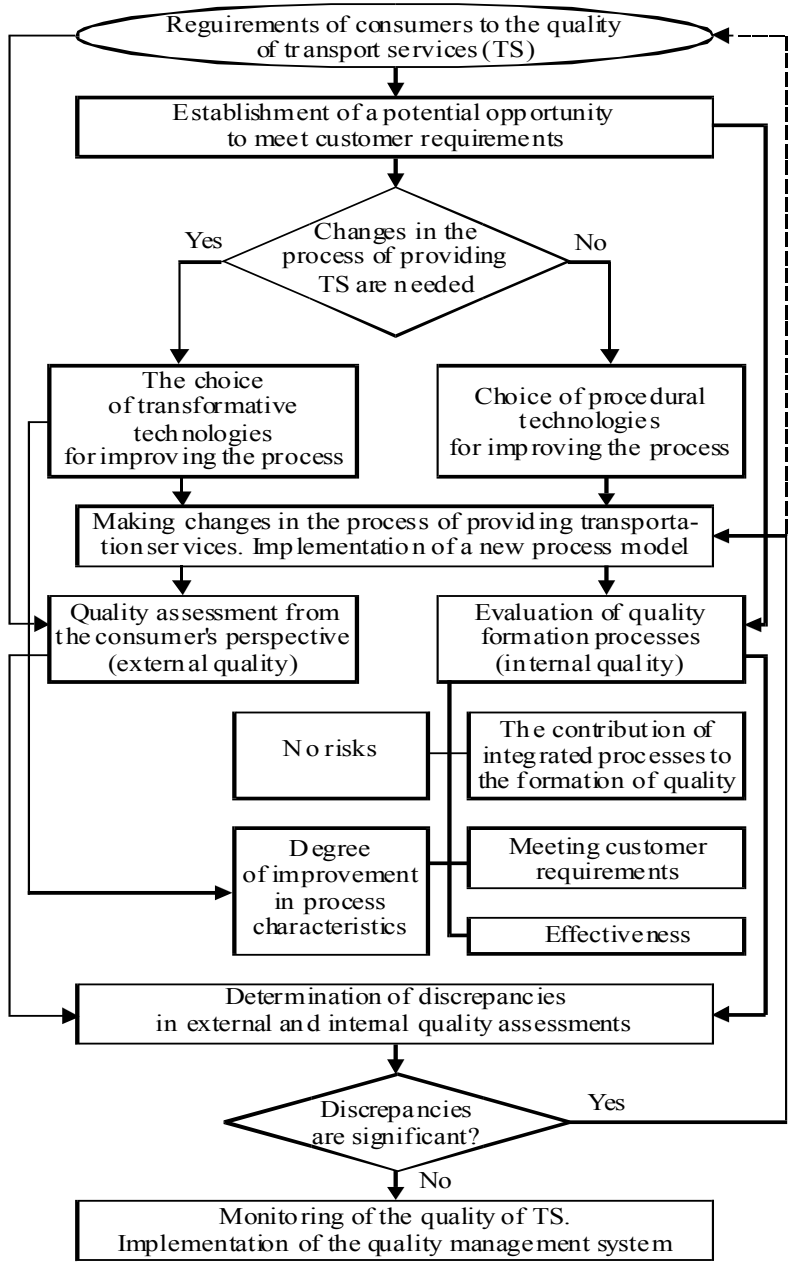

Fig. 4: The algorithm of operational quality management of transport services.

The evaluation of the processes of quality formation (internal quality) provides for determining the contribution of integrated processes to the quality of transport service, the fulfillment of consumers' requirements (internal users), the effectiveness, the absence of risks and the degree of improvement in the characteristics of the service. The integrated processes include: the processes of the consumer's activities (related to his actions to decide on the consumption of the service and its commission); customer service processes (receipt and registration of an order for motor transport services, and spontaneous provision of services (cargo preparation, loading, transportation, unloading and other operations required and requested by the customer), final operations (reception of cargo and/or provision of information concerning the completion of a service); auxiliary processes (related to ensuring the normal functioning of the service provision process, i.e. nightly servicing, diagnosis of faults, overhaul); total productive maintenance (directed to provide material resources, maintenance and repair of office equipment (for timely acceptance and registration of the service order, payments, etc.), cleanliness of premises and the territory of the ATE (to form a favorable enterprise image), etc. and managerial preparation processes.

Comparison of the two quality assessments and their discrepancies allows for taking further management decisions. In case of significant discrepancies, corrective actions are required. A complete or significant discrepancy between the external and internal quality means that the goals and objectives in the field of quality have not been achieved, the intervention of top management is required; the integrated processes require the development of significant and transformative changes.

\section{Conclusion}

The development of modern economy of transport enterprises is connected with quality management. The essence of the new concept of transport services quality management is the integration of the basic principles of TQM and logistics management. The introduction of logistics management, according to the experience of other countries, allows saving up to $15-20 \%$ of the costs of enterprises, while reducing logistic costs by $1 \%$ is equal to an increase in the volume by $10 \%$.

The application of the system paradigm of economic entities (enterprises and consumers) means changing the attitudes towards the relationship with consumers (including the consumer in the process of not only purchasing the service, but also in the overall process of the enterprise functioning: developing the service, assessing the quality, motivating the performers of the service, etc.).

Harmonization of the enterprise management system on the basis of quality is based on the following principles: hierarchy of the structure of the elements making up the system; integration with the company general management system; influence on production processes, but not on their results; change of the organizational structure of an enterprise to include the external and internal consumers in the process of providing transport services.

The proposed approach to transport services quality management will make it possible to form and more efficiently use the process control of the continuous "consumer-supplier-consumer" quality chain.

\section{References}

[1] Rui Chen, Yuan-Duen Lee \& Cheng-Hua Wang, "Total quality management and sustainable competitive advantage: seria mediation of transformational leadership and executive ability", Total Quality Management \& Business Excellence, Vol.29, (2018), https://doi.org/10.1080/14783363.2018.1476132

[2] Arawati Agusa \& Za'faran Hassanb "Enhancing Production Performance and Customer Performance Through Total Quality Management (TQM): Strategies For Competitive Advantage", Procedia - Social and Behavioral Sciences, Vol. 24, (2011), pp. 1650-1662, https://doi.org/10.1016/j.sbspro.2011.09.019

[3] Basu Ron \& J. Nevan Wright, Quality Beyond Six Sigma, Elsevier, (2003).

[4] Karel Havlíček, Pavla Břečková \& Vicky Zampeta, "Quality Management as a Part of CRM", European Research Studies, Vol. XVI, Special Issue on SMEs, (2013), pp.15-27.

[5] Jochen Wirtz \& Valarie Zeithaml, "Cost-effective service excellence", Journal of the Academy of Marketing Science, Vol. 46, Iss. 1, pp. 59-80, available online: https://link.springer.com/article/10.1007/s11747-017-05607/fulltext.html, last visit: January 2018.

[6] Fu Xuemei \& Juan Zhicai, "Exploring the psychosocial factors associated with public transportation usage and examining the "gendered" difference", Transportation research part a-policy and practice, Vol.103, (2017), pp. 70-72, http://dx.doi.org 10.1016/j.tra

[7] Costa Alvaro \& Fernandes Ruben, "Urban public transport in Europe: Technology diffusion and market organization", Journal of Transportation Research, Part A: Policy and Practice, Vol. 46, No. 2, (2012), pp. 269-284.

[8] W.M.P. van der Aalst \&A.W. Waltmans, "Modelling logistic systems with exspect", Dynamic Modelling of Information Systems, Vol.11, (1991), p. 269-287, https://doi.org/10.1016/B978-0-444-889232.50014-8

[9] Bierwirth C. "Adaptive Search and the Management of Logistic Systems: Base Models for Learning Agents", Springer Science \& Business Media, Vol.11, (2000), 219 p.

[10] Eboli L. \& Mazzulla G., "Performance indicators for an objective measure of public transport service quality", Trasporti Europei, Iss. 51, No. 3, (2012), pp.1-21. 